\title{
Niles J. Hasselquist, March 4, 1978 - January 8, 2021
}

Published online: 7 May 2021

๑) Springer Science+Business Media, LLC, part of Springer Nature 2021

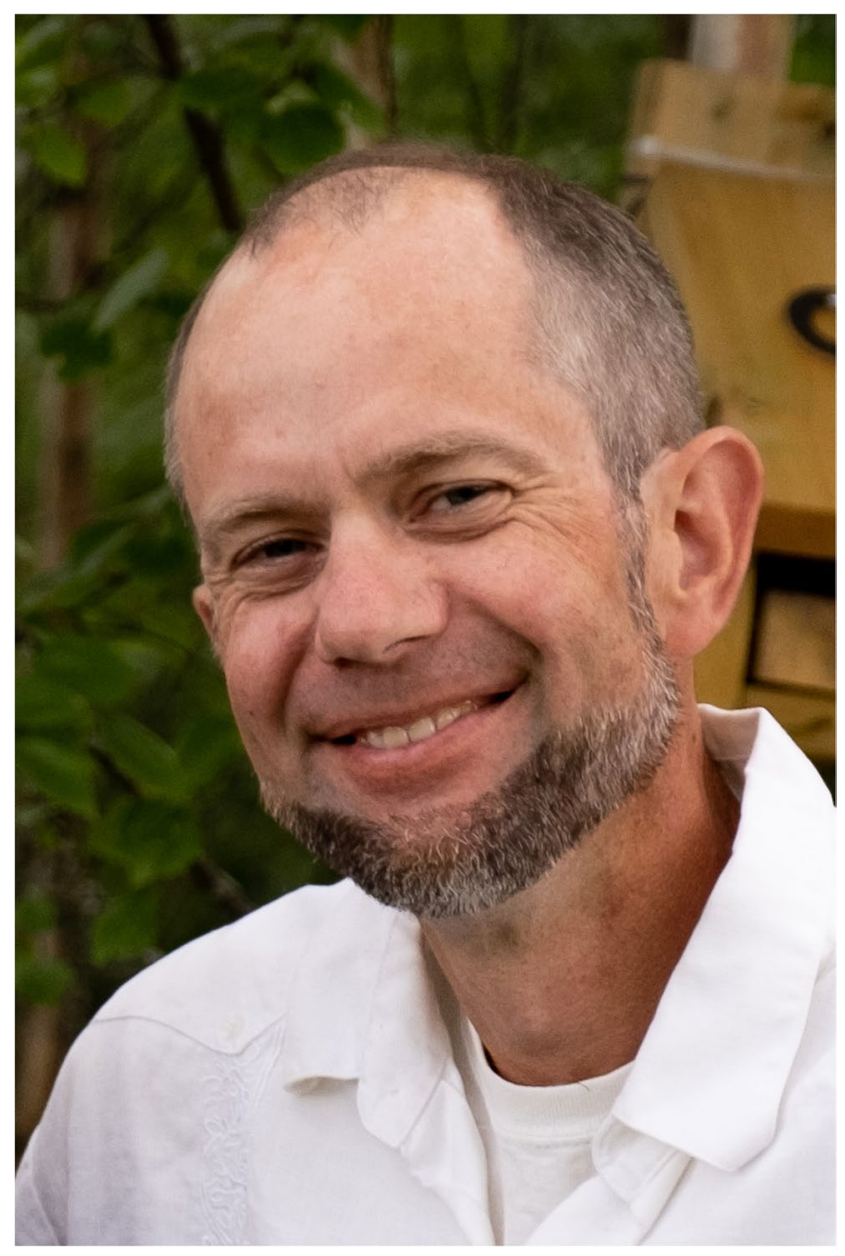

We dedicate this collection to Niles who made a major contribution to the workshop from which this cluster of papers emerged. He was also the inspiration behind Fig. 1 in the lead paper and the ideas around it. We are glad that he lived to see the paper published before he died. We so enjoyed working with him that we drew him into a research project on Secondary Forest in the Peruvian Amazon for which we secured funding at the end of 2020. His untimely death in Umeå, Sweden, after a courageous battle with stomach cancer was a shock to everyone and a great loss to his family, friends and colleagues. Niles was an enthusiast in his work and in his life to which he brought a great passion, a sharp mind and a big heart. He will be sorely missed. Niles is survived by his wife Eliza, daughter Frida, and son Tobias.

Niles grew up in Idaho, USA, took his undergraduate degree in Plant Biology at the University of California Berkeley in 2000, gained a Master's of Science in Biology from Idaho State University 2004 and completed his Ph.D. in Plant Pathology from University of California Riverside in 2009. After his $\mathrm{PhD}$, he completed a postdoc at Idaho State, working on the soil biogeochemistry of fire and deserts. Niles then moved to Sweden and began working on mycorrhizae and boreal forest ecology at the Swedish University of Agricultural Sciences in Umeå, where he later became an Instructor and Researcher. He taught courses in mycology, vegetation ecology and ecosystem functioning, and led research on ecosystem processes ranging from local Swedish boreal forests to forests of Mediterranean, African, and Southeast Asian ecosystems. He mentored a number of MS and $\mathrm{PhD}$ students and postdoctoral fellows, and published more than 30 refereed papers in mycorrhizal ecology and ecosystem dynamics. In 2018, Niles was promoted to Docent (Associate Professor) at the Swedish University of Agricultural Sciences.

Publisher's Note Springer Nature remains neutral with regard to jurisdictional claims in published maps and institutional affiliations. 